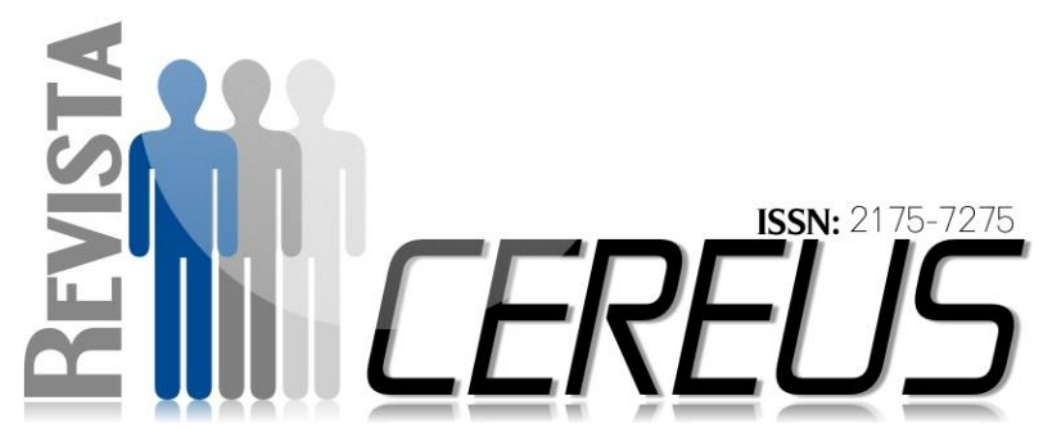

DOI:10.18605/2175-7275/cereus.v9n1p.3-17

\title{
A INTERDISCIPLINARIDADE E A EDUCAÇÃO AMBIENTAL NA PRÁTICA DOCENTE
}

GUILHERME, Laianne Souza ${ }^{1}$ SANTOS, Pedro Silva ${ }^{1}$

OLIVEIRA, José Lucas Santos² CAVALCANTE, Anna Fernanda Beatriz Amorim ${ }^{1}$ SILVA, Edevaldo ${ }^{3}$

\section{RESUMO}

A educação é um processo formativo do cidadão que visa transmitir os conhecimentos adquiridos para o próximo, com ênfase em um pensamento crítico e reflexivo. $O$ objetivo desta pesquisa foi de analisar o conhecimento e o uso da interdisciplinaridade e a Educação Ambiental na prática docente. Foram entrevistados 18 professores de duas escolas do ensino público de Catingueira, Paraíba. Os dados foram coletados por meio de um questionário contendo 25 afirmativas sendo e três questões discursivas. Além de outras variáveis

\footnotetext{
${ }^{1}$ Biólogos pela Universidade Federal de Campina Grande (UFCG)

2 Mestrando pelo Pós-Graduação Desenvolvimento e Meio Ambiente pela Universidade Federal da Paraíba (PRODEMA - UFPB)

3 Doutor em Química pela Universidade Federal da Bahia. Professor do Programa de PósGraduação Desenvolvimento e Meio Ambiente pela Universidade Federal da Paraíba (PRODEMA - UFPB) e Professor Adjunto da UFCG. E mail para correspondência: edevaldos@yahoo.com.br
}

v. 9, n. 1, jan/abr. 2017 UnirG, Gurupi, TO, Brasil 
(gênero, idade, titulação, tempo de ensino). Os professores $(72,2 \%, n=13)$ demonstraram possuir conhecimento sobre o uso da interdisciplinaridade em um contexto ambiental, e $(61,0 \%, n=11)$, realizam atividades práticas com temas ambientais. $(66,7 \%, \mathrm{n}=12)$ relataram a capacidade da interdisciplinaridade está envolvida em um contexto de diversos conteúdos, enquanto $33,3 \%(n=6)$ encontram dificuldades em apresentar um ensino interdisciplinar devido, principalmente, a capacitação pessoal $(72,2 \%, n=13)$ e a falta de parcerias $(61,1 \%, n=11)$. Houve correlação significativa $(p<0,001)$ entre o tempo de ensino do professor e a sua percepção de que o envolvimento dos assuntos de maneira interdisciplinar. Assim, é necessário estimular os alunos a assistirem as aulas e possivelmente motivar os professores a buscarem melhor capacitação para abordar um ensino de qualidade e inserir a Educação Ambiental de maneira interdisciplinar no currículo escolar abrangendo diversas áreas do conhecimento.

Palavras-chave: Pluridisciplinaridade. Educação Ambiental. docente.

\section{INTERDISCIPLINARITY AND ENVIRONMENTAL EDUCATION IN TEACHING PRACTICE}

\section{ABSTRACT}

Education is a formative process of the citizen that aims to transmit the acquired knowledge to the next one, with emphasis on a critical and reflective thought. The objective of this research was to analyze the knowledge and the use of interdisciplinarity and Environmental Education in teaching practice. We interviewed 18 teachers from two public schools in Catingueira, Paraíba. The data were collected through a questionnaire containing 25 statements and three essay questions. In addition to other variables (gender, age, education, teaching time). Teachers $(72.2 \%, \mathrm{n}=13)$ demonstrated to have knowledge about the use of

v. 9, n. 1 jan/abr. 2017 UnirG, Gurupi, TO, Brasil 
interdisciplinarity in an environmental context, and $(61.0 \%, \mathrm{n}=$ 11) performed practical activities with environmental themes. $(66.7 \%, n=12)$ reported the capacity of interdisciplinarity is involved in a context of diverse contents, $(33.3 \%, n=6)$ find difficulties in presenting an interdisciplinary teaching mainly due to $(72,2 \%, N=13)$, personal training and $(61.1 \%, n=11)$ and lack of partnerships. There was a significant correlation ( $p$ $<0.001)$ betwe environmental context, and 61.0\% ( $n=11)$, perform practical activities with environmental themes. $66.7 \%$ (n $=12$ ) reported the ability to interdisciplinarity is involved in a context of diverse content $(33.3 \%, \mathrm{n}=6)$ are difficulties in providing an interdisciplinary education, mainly due to personnel training $(72,2 \%, n=13)$ and lack of partners $(61.1 \%$, $n=11$ ).en the teaching time of the teacher and his perception of the involvement of the subjects in an interdisciplinary way. Thus, it is necessary to encourage students to attend classes and possibly motivate teachers to seek better training to approach quality education and to insert Environmental Education in an interdisciplinary way in the school curriculum covering several areas of knowledge.

Key words: Pluridisciplinarity. Environmental. Education, teacher. 


\section{INTRODUÇÃO}

A interdisciplinaridade compreende uma maneira de articulação dos saberes docentes, tendo em vista a necessidade de reflexão sobre sua importância no processo ensino-aprendizagem (SOUSA; BASTOS, 2016), proporcionando melhor compreensão sobre o tema abordado, mesmo que em disciplinas distintas (ROSO; AULER, 2016).

A fragmentação disciplinar pode ser considerada como limitação no entendimento de diversos temas, pois, a construção do conhecimento de forma coletiva aproxima as diversas áreas das ciências, permitindo relações mais dinâmicas e eficientes no contexto educacional (COSTA; LOUREIRO, 2015).

A educação é um misto de conhecimentos e técnicas que visa à objetividade e eficácia na formação do cidadão, é uma forma especial de transpassar para o próximo tudo que pode ser importante no enriquecimento de um pensamento crítico e reflexivo (FREIRE; NOGUEIRA, 1993).

O conhecimento é fruto da união e construção de ideias que induzem a interpretação e induzem a interpretação e conhecimento seja con
Rev. Cereus, v. 9, n. 1, p.03-17, jan-abr./2017, UnirG, Gurupi, TO, Brasil.

entendimento de determinado conteúdo com percepção mais elaborada, favorecendo a capacidade de raciocinar e distinguir o que pode ser importante ou não para o amadurecimento intelectual e social do indivíduo (MORIN, 2000).

É necessário que haja mudanças no processo educacional, de maneira a organizar e construir o conhecimento de forma sistemática, com inovações que proporcione a edificação de determinado saber, mas também promovendo interações educacionais entre as diferentes áreas do conhecimento (BOFF, 2003).

O diálogo de profissionais de diversas áreas sobre um tema especifico, constitui um conhecimento interdisciplinar, favorecendo o entendimento de mútuas determinações que antes eram abordadas de maneira isolada (SOUSA; BASTOS, 2016).

A Educação Ambiental promove essa interdisciplinaridade, por negar a fragmentação do conhecimento e da abordagem dos conteúdos de forma isolada entre as ciências e as disciplinas, contribuindo para que o conhecimento seja construído com a 
relação harmoniosa entre o homem e a natureza que o cerca (COSTA; LOUREIRO, 2015), destacando-se por seu aprendizado contínuo e vertente de sensibilização social quanto a preservação e conservação do ambiente (OLIVEIRA et al., 2016).

Nesse contexto, o Plano Nacional de Educação Ambiental PNEA, define que:

A Educação Ambiental é um componente essencial e permanente da educação nacional, devendo estar presente, de forma articulada, em todos os níveis e modalidades do processo educativo, em caráter formal e não-formal, como parte do processo educativo mais amplo, todos têm direito à educação ambiental (Brasil, 1999, p.01).

A educação deve romper com essa visão simplista de que o conhecimento deve ser fragmentado, quando na verdade a interdisciplinaridade possibilita a associação de diversos saberes e conteúdos no contexto escolar,

\section{MATERIAIS E MÉTODOS}

A pesquisa foi realizada em duas escolas: Escola Municipal de Ensino Fundamental Maria Celeste Pires Leite e na Escola Estadual de Ensino Fundamental e Médio Inácio da Catingueira, localizadas em formando cidadãos conscientes capazes de atuar positivamente na sociedade (QUADROS et al., 2016), assim como a inserção da Educação Ambiental na escola (COSTA; LOUREIRO, 2015).

A prática docente, associada a formação continuada, induz ao docente obter melhor flexibilidade $\mathrm{e}$ segurança para abordar temas diferentes, que quando unidos, sejam capazes de ampliar a compreensão da importância do conteúdo para a sociedade (DEVECHI et al., 2016), além de melhorar a resposta a condições adversas que podem vir a ocorrer em sala de aula (SOARES et al., 2016).

O objetivo desta pesquisa foi analisar o conhecimento e o uso da interdisciplinaridade e a Educação Ambiental na prática docente.

Catingueira, Paraíba (Figura 1), município com densidade demográfica de 9,09 hab/km² e população 4.812 habitantes (IBGE, 2010). 
Figura 1 - Mapa da localização do município de Catingueira, Paraíba.

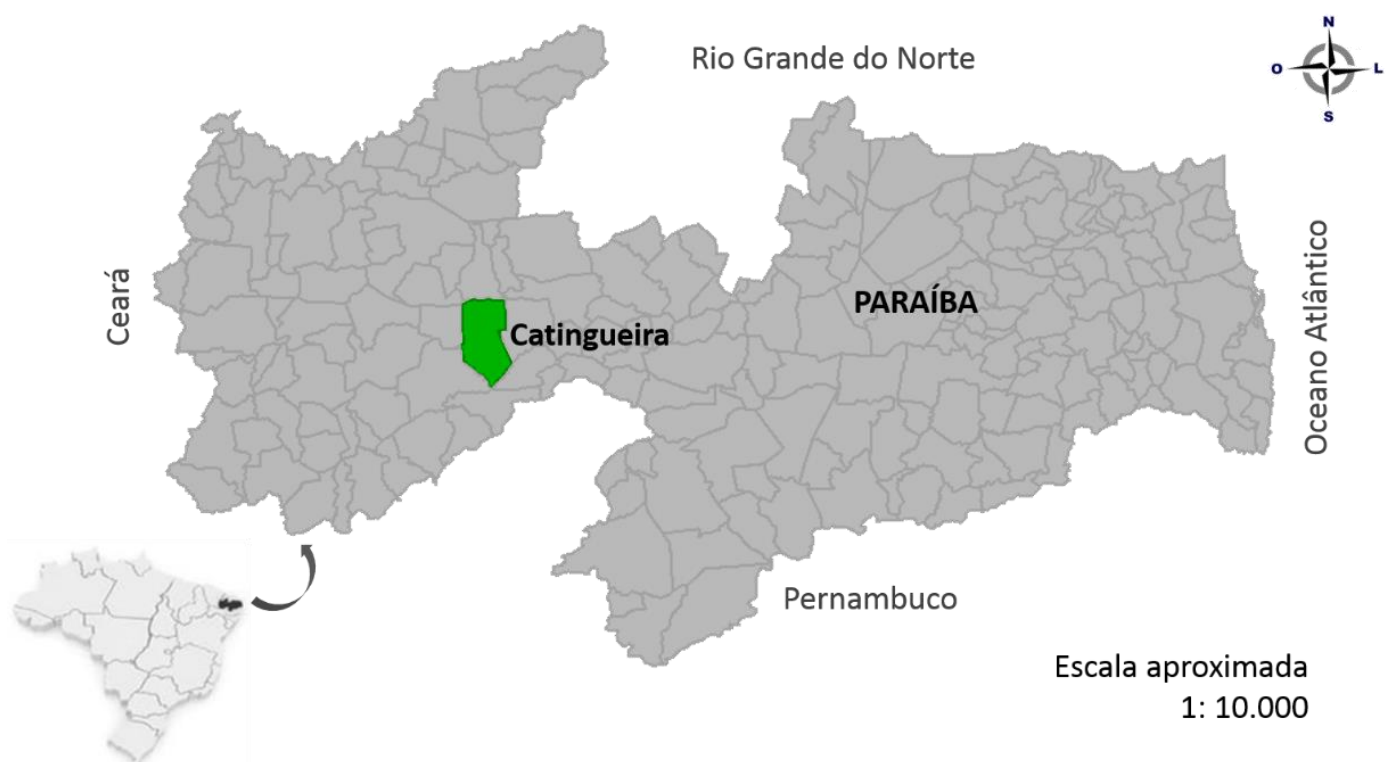

O tamanho amostral foi estatística descritiva, utilizando o estabelecido segundo Rocha (1997), a partir do número total de professores software Microsoft Excel 2013.

Além das afirmativas em Likert, que lecionam nas duas escolas, o questionário continha três questões considerando o erro padrão de $10 \%$. discursivas, a saber: "O que é Então, a amostragem estabelecida foi interdisciplinaridade?", "Você realiza de 18 professores realizada de forma atividades com os alunos fora da aleatória simples.

Os dados foram coletados durante $\mathrm{o}$ ano de 2016 por meio da aplicação de um questionário com 25 afirmativas de múltipla escolha segundo a escala de Likert (Nível 1 Concorda completamente à Nível 5 Discorda completamente). A análise das respostas foi por meio da escola? Se sim, quais?" e "O que é Educação Ambiental?". Foi avaliado ainda o perfil do professor (tempo de ensino público, titulação) e variáveis de classificação (sexo, idade). A análise das respostas discursivas foi avaliada de forma qualitativa e quantitativa.

Para a análise de correlação entre o tempo de ensino $e$ as 
respostas dos professores quanto a aplicabilidade do ensino interdisciplinar em sua disciplina foi por meio da correlação de Spearman, considerando o nível de significância

\section{RESULTADOS E DISCUSSÃO}

Foram entrevistados 18 professores, onde 61,1\% ( $\mathrm{n}=11)$ eram do gênero feminino e 38,9\% ( $n=$ 7) do gênero masculino, com idades entre 26 e 51 anos e tempo de ensino variando de 2 meses a 28 anos. Eles (61,0\%, $n=11)$, possuíam nível de especialização na área em que leciona, enquanto que $(22,2 \%, n=4)$ concluíram apenas a graduação, $(16,7 \%, n=3)$ são mestres.

Dentre os professores entrevistados, $72,2 \% \quad(n=13)$ conceituaram a interdisciplinaridade de forma correta. Usualmente o conceito de interdisciplinaridade atribui-se aquilo que auxilia na relação entre os conhecimentos das diferentes disciplinas do currículo formal, onde também potencializa as técnicas envolvendo a contextualização e aprendizagem de temas transversais, $p<0,001$ e utilizando o software SPSS 20.0 .

já que envolve mais de uma disciplina no processo de ensino (CÓRDULA; FÔNSECA, 2012).

Os resultados reportaram que $72,2 \%$ ( $n=13)$ dos professores relacionam a Educação Ambiental a um contexto apenas de um ambiente que precisa ser preservado e respeitado, excluindo o ser humano como participante da natureza. A partir dessa percepção os alunos não conseguem ver a si próprios como pessoas que precisam cuidar da natureza, visto que associam o meio ambiente a um local que não precisa da ajuda do homem.

Os professores, 61,0\% $(n=11)$ afirmaram realizar aulas práticas no campo com os alunos, constituindo-se como um aspecto positivo diante do processo de ensino-aprendizagem, para que os alunos possam se relacionar mais com a natureza.

Para Boff (2003), é fundamental a elaboração de um novo tipo de relação entre o ser humano e o meio 
ambiente, onde 0 desenvolvimento seja em conjunto, afim de proporcionar uma melhor percepção da população quanto a escassez dos recursos naturais.

Os professores $94,4 \%(n=17)$ reportaram compreender muito bem 0 conceito de interdisciplinaridade, e $77,8 \%(n=14)$ relataram dialogar sobre a interdisciplinaridade em suas disciplinas (Tabela 1).

Para Peleias et al., (2011), a interdisciplinaridade constitui-se como articuladora do processo de ensinoaprendizagem e um elemento fundamental na orientação dos profissionais da educação em sua formação.

Tabela 1 - Frequência (\%) do conhecimento e uso da interdisciplinaridade e Educação Ambiental do ponto de vista docente.

\begin{tabular}{l|c|c|c|c|c}
\hline \multicolumn{1}{c|}{ Item } & 1 & 2 & 3 & 4 & 5 \\
\hline $\begin{array}{l}\text { Costumo dialogar com meus alunos sobre temas } \\
\text { relacionados à Educação Ambiental }\end{array}$ & 0,0 & 11,1 & 11,1 & 27,8 & 50,0 \\
\hline $\begin{array}{l}\text { Sei o que é interdisciplinaridade } \\
\begin{array}{l}\text { A interdisciplinaridade é possível somente para } \\
\text { alguns assuntos }\end{array}\end{array}$ & 0,0 & 0,0 & 0,0 & 5,6 & 94,4 \\
\hline $\begin{array}{l}\text { Encontro dificuldades para trabalhar a Educação } \\
\text { Ambiental de maneira interdisciplinar }\end{array}$ & 27,8 & 27,8 & 5,6 & 27,8 & 0,0 \\
\hline $\begin{array}{l}\text { Já desenvolvi/participei de projetos } \\
\text { interdisciplinares }\end{array}$ & 5,6 & 5,6 & 11,1 & 22,2 & 11,1 \\
\hline $\begin{array}{l}\text { Tenho interesse em me capacitar em Educação } \\
\text { Ambiental }\end{array}$ & 5,6 & 0,0 & 11,1 & 33,3 & 61,1 \\
\hline $\begin{array}{l}\text { Já desenvolvi/participei de projetos em Educação } \\
\text { Ambiental }\end{array}$ & 16,7 & 11,1 & 11,1 & 11,1 & 50,0 \\
\hline \begin{tabular}{l} 
Estou satisfeito com meu trabalho \\
\hline
\end{tabular} & 0,0 & 5,6 & 16,7 & 27,8 & 50,0 \\
\hline
\end{tabular}

Legenda: 1 - Discordo completamente; 2 - Discordo em grande parte; 3 - Nem concordo e nem discordo; 4 - Concordo em grande parte; 5 - Concordo completamente

Os professores $66,7 \%(n=12)$ afirmaram que a interdisciplinaridade pode estar envolvida em um contexto de diversos conteúdos, $72,2 \%(n=13)$ deles já tiveram experiência em projetos interdisciplinares. Além disso, 
$33,3 \%(n=6)$, afirmaram que encontram dificuldades para trabalhar a temática ambiental de maneira interdisciplinar. Segundo eles, quase metade $38,9 \%(n=7)$ os alunos não possuem interesse nas aulas (Figura 2).

Figura 2 - Frequência (\%) do nível de dificuldade docente para um ensino interdisciplinar segundo os diversos aspectos que influenciam no ensino.

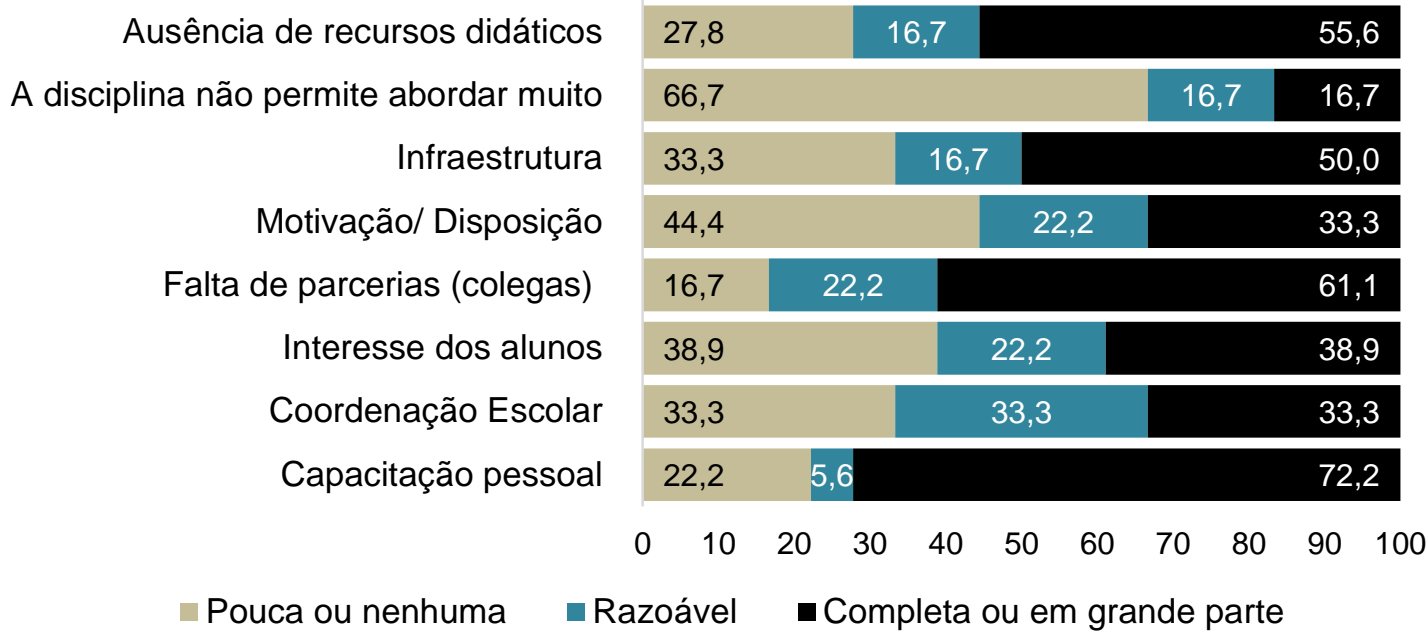

De acordo com Machados; tradicional, e não tem o domínio da Batista, (2012), a ligação entre as diversas disciplinas promove 0 fortalecimento da interdisciplinaridade, respeitando acima de tudo suas particularidades, para propiciar a possibilidade de um pensar em conjunto desenvolvendo a inteligência.

Sousa e Bastos, (2016), relataram resultados diferentes aos aqui reportados, onde os coordenadores de cursos de Farmácia da região Centro-Oeste, tiveram suas formações no modelo de ensino prática de como trabalhar a interdisciplinaridade.

Para Ribeiro e Bueno, (2015), poucos professores estão capacitados para utilizar a interdisciplinaridade em seus métodos de aula, devido terem sido formados a partir de um ensino fragmentado, separado em várias áreas do conhecimento.

No que se refere a Educação Ambiental, $83,3 \% \quad(n=15)$ dos professores tinham vontade de se capacitação nessa área, onde $61,1 \%$ 
( $\mathrm{n}=11$ ) já possuíram envolvimento com projetos relacionados a Educação Ambiental.

A capacitação desses professores pode ter bons resultados por que $77,8 \%(n=14)$ são satisfeitos com o trabalho. E a capacitação pode melhorar a sua motivação, visto que quase metade deles afirmaram estar pouco motivados (Figura 2). Para Freire (1997) quanto mais tolerantes, naturais, humildes e críticos os professores forem maior capacidade eles terão de exercer a prática docente.

Os professores entrevistados afirmaram que a disciplina muitas vezes não permite a interdisciplinaridade (Figura 2). Dessa forma, é possível que eles se percebam, equivocadamente, como tendo uma abordagem interdisciplinar satisfatória.

Além disso, foi observada correlação significativa entre o tempo de ensino do professor e a sua percepção de que o envolvimento dos assuntos de maneira interdisciplinar, onde professores com mais tempo de ensino tenderam a afirmar que a abordagem interdisciplinar não é sempre possível (Figura 3). Essa correlação corrobora com a necessidade de capacitação docente, incluindo aqueles que estão a mais tempo envolvidos com o ensino.

Figura 3 - Frequência (\%) da satisfação do docente quanto a abordagem dos diferentes temas ambientais.

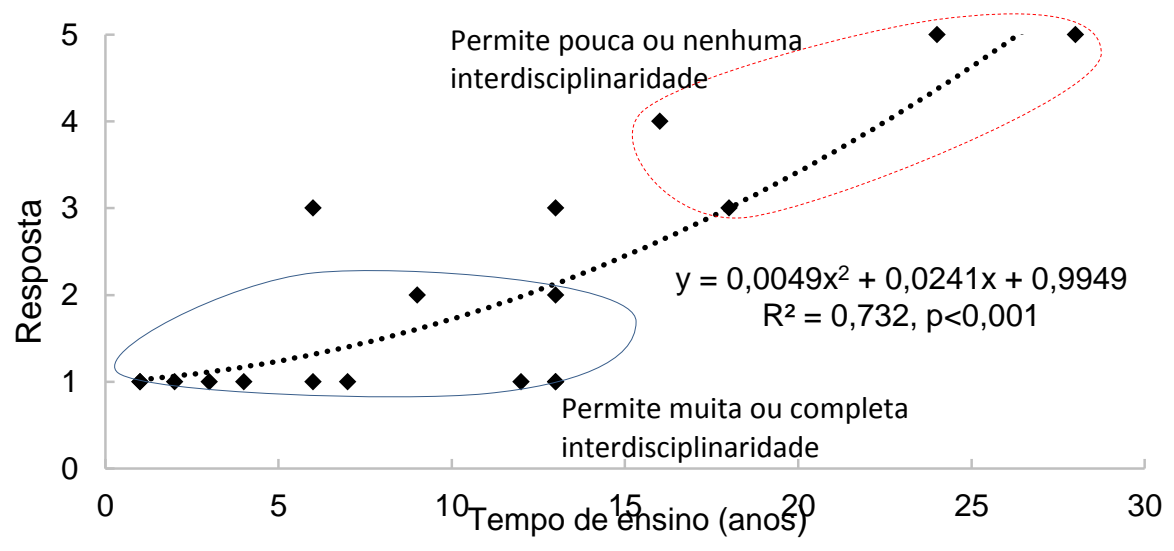

Para Velloso et al., (2016) a ser constante em todas as aulas, busca pela interdisciplinaridade deve assim ocasiona um maior interesse e 
envolvimento dos alunos na busca por novos conhecimentos, e tornando-se estimulante para os professores.

Os professores 55,6\% $(n=11)$, relataram que a falta de recursos didáticos que auxilie em suas aulas é um fator bastante negativo para trabalhar de maneira interdisciplinar. Eles $66,7 \%(n=13)$, relataram que 0 maior problema de inserção da Educação Ambiental de maneira interdisciplinar não está relacionado a capacidade de abordagem em sua disciplina, mas 72,2\% ( $\mathrm{n}=13)$, abordaram que o maior problema ainda é a capacitação pessoal.

Além disso, os professores apontaram outras dificuldades para trabalhar a Educação Ambiental de maneira interdisciplinar. Eles indicaram que essas dificuldades eram relacionadas, principalmente, à: a infraestrutura $(50,0 \%, n=9)$, falta de motivação e/ou disposição (33,3\%, n = 6), ausência de parcerias para trabalhar $(61,1 \%, n=11)$ e falta de apoio da coordenação escolar (38,9\%, $\mathrm{n}=7)$.

Neto e Amaral, (2011), relataram resultados similares em sua pesquisa, realizada com professores de Ciências do Ensino Fundamental II da cidade de Escada, Pernambuco, onde $58,4 \%$ apontaram que é difícil inserir Educação Ambiental na sala de aula, devido à ausência de aparelhamento nas escolas, capacitação dos professores, suporte financeiro para o professor entre outros.

De acordo com Biasibetti et al., (2015), o livro didático caracteriza-se por ser uma ferramenta importante para a aula, mas o modelo tradicional de ensino usado em muitas instituições de ensino faz com que o aluno não associe o conteúdo abordado com o contexto da sua realidade devido a abordagem ser pouco esclarecedora.

Para Almeida e Sartori, (2012), a desmotivação dos alunos em assistir as aulas tem impactos negativos no processo de ensino-aprendizagem, o planejamento e consequente desenvolvimento da aula é papel do professor, e assim se torna fatores determinantes para o bom convívio do aluno e docente.

Os professores são fundamentais na busca e aplicação de novos métodos de ensino e propostas interdisciplinares que despertem 0 interesse dos alunos. Trabalhar com Educação Ambiental de maneira interdisciplinar faz com que a 
aprendizagem se torne mais

para a maioria dos temas, significativa para que os alunos principalmente, aqueles relacionados entendam a relação existente entre o ao consumo consciente $(88,9 \%, \mathrm{n}=$ homem, o ambiente e o universo (BIASIBETTI et al., 2015).

16) e a preservação do ambiente $(77,8 \%, n=14 ;$ Figura 4).

Os professores julgam-se capazes de uma abordagem eficiente

Figura 4 - Frequência (\%) da satisfação do docente quanto a abordagem dos diferentes temas ambientais.

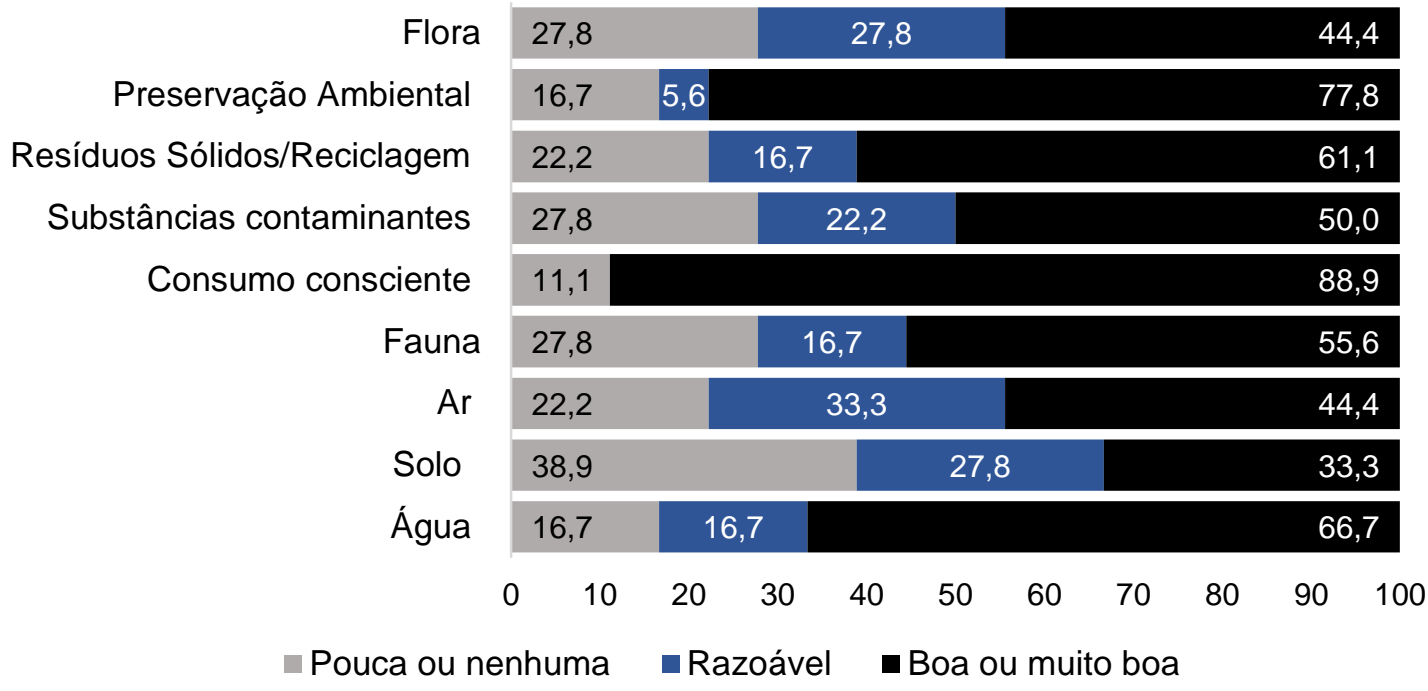

Dentre os temas ambientais mais frequentemente abordados estão: Flora $(44,4 \%, \mathrm{n}=8)$, Utilização de resíduos sólidos/Reciclagem (61,1\%, n
= 11), Uso de substancias contaminantes $(50,0 \%, \mathrm{n}=9)$, Fauna $(55,6 \%, n=10), \operatorname{Ar}(44,4 \%, n=8)$ e Água, $(66,7 \%, n=13)$.

\section{CONCLUSÕES}

Os professores entrevistados afirmam saber 0 conceito de interdisciplinaridade, e conseguir aplicar em suas aulas, e reportam que a Educação Ambiental é possível abranger várias disciplinas, porém, 
alguns docentes ainda estão com dificuldades em aplicar este método de ensino nas suas aulas, principalmente devido à falta de capacitação pessoal, falta de parcerias e ausência de recursos didáticos que auxiliem em suas aulas. Alguns professores tiveram dificuldades em conceituar de forma correta a Educação Ambiental.
É necessário estimular os alunos a assistirem as aulas $e$ possivelmente motivar os professores a buscarem melhor capacitação para abordar um ensino de qualidade e inserir a Educação Ambiental de maneira interdisciplinar no currículo escolar abrangendo diversas áreas do conhecimento.

\section{REFERÊNCIAS}

ALMEIDA, T. F. S.; SARTORI, J. A relação entre desmotivação e o processo ensino-aprendizagem. Revista de Monografias Ambientais, v. 8, n. 8, 2012a, p. $1870-1886$.

BIASIBETTI, L.; TREVISAN, M. L.; NISHIJIMA, T.; PERES, P. E. C. A concepção dos educadores sobre a temática de educação ambiental na escola: dificuldades e desafios. Revista Monografias Ambientais, v. 14, n. 2, 2015a, p. 220-237.

BOFF, L. A ética na formação de valores na sociedade. 4. ed. São Paulo: Instituto Ethos, 2003.

BRASIL, Plano Nacional de Educação Ambiental - PNEA, 1999, 01 p.

CÓRDULA, E. B. L., FÔNSECA, P. N. Análise da interpretação sobre educação ambiental, dos profissionais atuantes em uma escola pública municipal de Cabedelo-PB. Revista Educação Ambiental em Ação. n. 39, 2012.

COSTA, C. A. S.; LOUREIRO, C. F. B. Interdisciplinaridade e educação ambiental crítica: questões epistemológicas a partir do materialismo históricodialético. Ciência e Educação, v. 21, n. 3, 2015a, p. 693-708.

DEVECHI, C. P. V.; TAUCHEN, G.; TREVISAN, A. L. Aprendizagem evolutiva na formação de professores: continuidade entre as certezas da ação e os acertos discursivos. Revista Brasileira de Educação, v. 21, n. 65, 2016a, p. 347-369. 
FREIRE, P.; NOGUEIRA, A. Teoria e prática em educação popular. 4. ed. Petrópolis: Vozes, 1993.

IBGE. IBGE | Cidades | Paraíba | Catingueira. (2010). Disponível em: $<$ http://cidades.ibge.gov.br/xtras/perfil.php?codmun=250420> Acesso em: 20 de nov. 2016.

MACHADOS, M. M. B. C.; BATISTA, S. H. S. S. Interdisciplinaridade na Construção dos Conteúdos Curriculares do Curso Médico. Revista Brasileira de Educação Médica, v. 36, n. 4, 2012a, p. 456-462.

MORIN, E. Educação e complexidade: Os sete saberes e outros ensaios. 4. ed. São Paulo, 2007.

MORIN, E. Os sete saberes necessários à educação do futuro. Unesco, Brasília, 2000.

NETO, A. L. G. C.; AMARAL, E. M. R. Análise de concepções e visões de professores de ciências sobre educação ambiental. Pesquisa em Educação Ambiental, v. 6, n. 2, 2011a, p. 119-136.

OLIVEIRA, J. L. S.; SILVA, E.; OLIVEIRA, H. M.; SILVA, R. D.; LIMA, J. R.; RÊGO, V. G. S. Gestão de resíduos sólidos em Patos, Paraíba: Um olhar sobre a coleta seletiva na escola e no comércio. Revista Espacios, v. 37, n. 7, 2016a. p. 8.

PELEIAS, I. R.; MENDONÇA, J. F.; SLOMSKI, V, G.; FAZENDA, I. C. A. Interdisciplinaridade no ensino superior: análise da percepção de professores de controladoria em cursos de Ciências Contábeis na cidade de São Paulo.

Avaliação: Revista da Avaliação da Educação Superior, v. 16, n. 3, 2011 a, p. 499-532.

QUADROS, A. L.; PENA, D. M. B.; FREITAS, M. L.; CARMO, N. H. S. A Contribuição do Estágio no Entendimento do Papel do Professor de Química. Educação e Realidade, v. 41, n. 3, 2016a, p. 889-910.

RIBEIRO, L. F.; BUENO, B. A educação do campo e a interdisciplinaridade: desafios e possibilidades. Revista Monografias Ambientais, v. 14, 2015a, p. $121-130$.

ROSO, C. C.; AULER, D. A participação na construção do currículo: práticas educativas vinculadas ao movimento CTS. Ciência e Educação, v. 22, n. 2, 2016a, p. 371-389. 
SOARES, E. S.; PAULA, G. M. M.; VIEIRA, M. L. Aprendizagens no contexto de uma atividade: um confronto teórico analisado a partir de um exemplo prático. Revista Brasileira de Educação, v. 21, n. 65, 2016a, p. 477-503.

SOUSA, I. F.; BASTOS, P. R. H. O. Interdisciplinaridade e formação na área de farmácia. Revista Trabalho, Educação e Saúde, v. 14, n. 1, 2016a, p. 97-117.

VELLOSO, M. P.; GUIMARÃES, M. B. L.; CRUZ, C. R. R.; NEVES, T. C. C. Interdisciplinaridade e formação na área de saúde coletiva. Revista Trabalho, Educação e Saúde, v. 14, n. 1, 2016a, p. 257-271.

Recebido em: 21/11/2016.

Aprovado em: 02/03/2017. 